\title{
Study on the Quality Improvement through Analysis of the Cause of the Structure Design Drawing in the Internal Reinforced Concrete Structures
}

\author{
Kim, Byung-Yun* \\ Department of Architectural Engineering, Kwandong University, Gangneung, 210-701, Korea
}

\begin{abstract}
The cause of crack on reinforced concrete structures is varied, while the studies, which have intended to analyze this in the material side, have been the mainstream so far. Therefore, in this study, we intended to suggest the proposals for enhancement of the system to reduce crack and to improve the quality of the reinforced concrete structures, by reviewing the cause of crack mainly in the structural aspect and analyzing the practices and the system. The result has been shown as following. (1) As one of the measures for improving the constructional system related to the structure, it is to enhance the relevant system so that design on construction, structure, and equipment, can be separately ordered or jointly ventured, and the owner or the agent of the owner can discuss and mediate the business in each specialized field. (2) Importance on construction supervision and new establishment of regulations related to structure supervision.s
\end{abstract}

Keywords : structure crack, structure design, separate order, joint venture

\section{Introduction}

\subsection{Research background and objective}

Concrete in in wide use for building structures and civil structure due to its relative affordability and easy formation into any shape. However, its weak characteristics to tensile force unavoidably brought about cracks on concrete. To complete this sort of weakness, reinforcement material, representative of rebar, is composed in part of building structures. When the rebars are not placed in a right place, it is highly likely to have cracks on concrete surface upon any load on the structural members. For this reason, structure design criteria of nations around the world always specify details related with the prin-

Received : November 1, 2013

Revision received : December 17, 2013

Accepted : January 3, 2014

* Corresponding author : Kim, Byung-Yun

[Tel: 82-33-649-7528, E-mail: kby@kd.ac.kr]

(c)2014 The Korea Institute of Building Construction, All rights reserved. ciples of rebar placement. The reasons of incorrect rebar placement are various: any errors in structural design, omission or incompleteness of the specification of rebar placement, or different placement of rebars from the design. There are many different causes found for the cracks on concrete structures, but the studies have focused on analyzing the causes from the perspective of materials.

Thus, this study probes the causes of cracks from the structural perspective and analyzes the practices related with the cracks, and proposes an improvement plan for quality and reduction in cracks on rebar concrete structures built based on structural drawings.

\subsection{Research scope and methodology}

The scope of this research is to analyze the causes of cracks found on the building structures from the structural perspective, and to propose an improvement plan through a study on practices for crack reduction. To effectively attain the research ob- 
jective, literature review was first conducted, and then followed by a questionnaire survey and interviews, an analysis of structural drawings and filed research.

\section{Literature review related with defects in building structures}

\subsection{Research methodology}

To review previous studies related with defects in concrete building structures, related information was searched from the database of Civil Engineering Research Information Center[1] and Architecture and Urban Research Information Center[2]. A total of 1,238 research papers, research reports, journals and books were extracted. Of the information, 79 literatures were primarily extracted except for journals and newspaper articles that are not highly reliable. The 79 literatures were classified into 7 categories: defect management, causes and measures, guarantee for defects, dispute, defect cases, system, and criteria. Of the literatures, the literatures that were not directly related were excluded and then 34 literatures were finally selected.

The 34 literatures finally selected were divided into 4 categories: causes and countermeasures, defect cases, criteria for defect determination, and management. Of them, 17 literatures include in the category of 'causes and measures,' which indicates that a large portion of previous studies has been done on causes and measures of crack defects.

\subsection{Major research trends}

An Yong Seon analyzed the defect-repair records from 10 apartment buildings located in Daegu and its neighboring area as an effort to analyze defect types and measures for the defects in 'A study on types and countermeasures against defects in constructing apartment houses.' Through the analysis, it was found that in terms of defect occurrence by process, $77 \%$ of defects arose out of construction, $14 \%$ out of equipment and facilities, and 9\% out of electricity, in that order. Based on the result, defects from construction was reported to be the greatest portion[3].

Go Seong Seok conducted a questionnaire survey for residents in apartment houses in Gwangju to analyze the time of defect occurrence in the research paper, 'Analysis of Defect Cases by Construction Types in Apartments.' From the analysis, it was revealed that approximate 50\% of all the defects occur within 2 years after the residents moved in, and by work type, defects occurred in 32\% of civil engineering work and $25 \%$ of construction work within a year[4].

From the results above, defects found in apartment houses occur at an early residence within 2 years of moving in, and the defects found after that are believed to have occurred out of composite causes related with maintenance problems.

Up to the 1990s defect related studies had been conducted mainly on the analysis of defect causes and technical countermeasures for the defects. However, since the 2000s when people have come to have a keen interest in such issues as improvement of quality of life, expansion of brand equity, and introduction of the concept of customer satisfaction, studies on the concept of defect management have been actively conducted. Accordingly, lawsuits against defects of apartment housing and the roles and management of defects dispute mediation committee have been researched.

In addition, with regard to key defect factors related with structure design, Park Seong Wuk categorized errors of structure design usually found in the design phase into four: (1insufficient review of design data, (2)errors of construction drawings, (3)errors of structural interpretation, and (4)errors of structure design documents. 


\section{Survey and interview}

\section{3,1 Questionnaire survey}

\subsubsection{Outline}

A total of 314 people participated in this survey, and Figure 1 indicates personal data, and years of work experience of the respondents. To be more specific, respondents who have more than 21 years of work experience accounted for $27 \%$, the largest proportion, while respondents who have less than 5 years work experience accounted for approximate $11 \%$, the smallest proportion. In terms of "professional engineer certificate holders, $55.1 \%$ of the respondents hold a professional engineer certificate, professional engineers were about $32 \%$, specifically consisting of professional engineers architectural execution(15.7\%), professional engineer structural execution(14.5\%), and $\operatorname{architects}(1.6 \%)$.

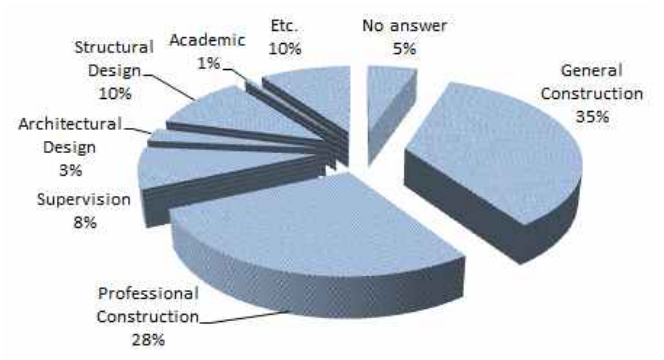

(a) Duty organ

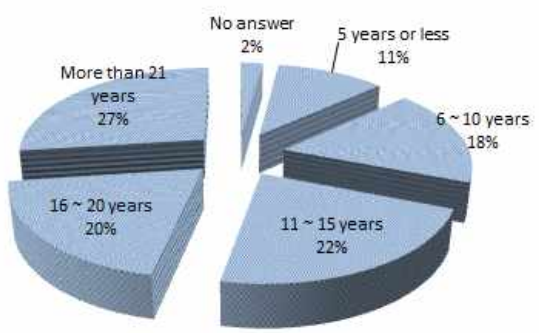

(b) Service period

Figure 1. Personal data of question investigation

3.1.2 Results and analysis of the questionnaire survey

1) Causes and parts of cracks on concrete
As shown in Figure 2(a), cracks were usually found at planar members including slab and wall, and especially on the openings and joints of the members. The 'main causes of cracks' were, as shown in Figure 2(b), related with construction(31.4\%), materi$\operatorname{als}(28.0 \%)$, and structure(25.0\%), three of which are a similar proportion, while environment(15.6\%) was relatively low. From the responses, as the causes of cracks on the building structures not only construction and materials but also structure should be dealt with seriously.

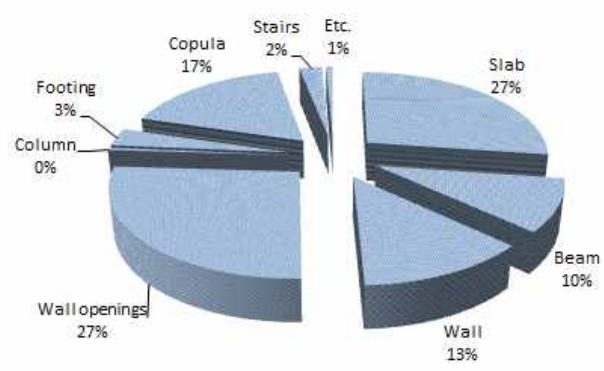

(a) Members of crack occurrence

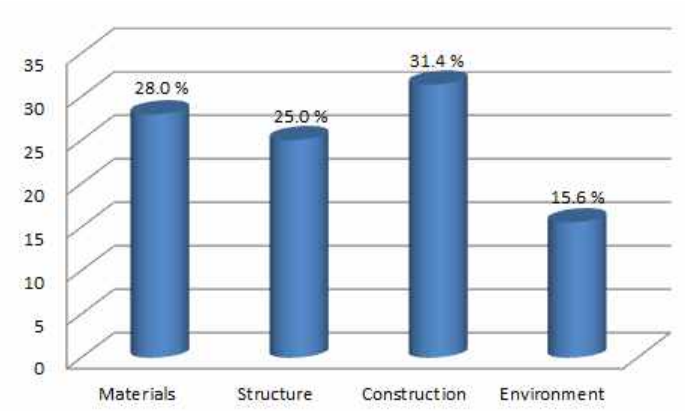

(b) Main cause of crack occurrence

Figure 2. Members and cause of crack occurrence in concrete

2) Structure design and shop drawing

For the question of the 'Are you satisfied with the construction drawings used in construction?,' 47.8\% of the respondents answered 'moderately' followed by 'overall satisfied(22.3\%)' and 'overall dissatisfied(21.0\%)' as shown in Figure 3(a). However, the proportion of each response was shown to be almost similar. 
As the structural information omitted from the drawings used in construction, detail drawings including joints and skip-floor(32.9\%), numerically expressed settlement/location/length of a joint(22.4\%), and cutoff points of rebar(21.3\%) were mentioned frequently, and location of the top rebar and the interval of rebars when placed in multiple layers(14.8\%), and sheath thickness $(7.1 \%)$ were also mentioned as you can see in Figure 3(b). Likewise, the drawings currently used in construction have much information omitted, and it is believed the omitted information must be included in the drawings for accurate construction.

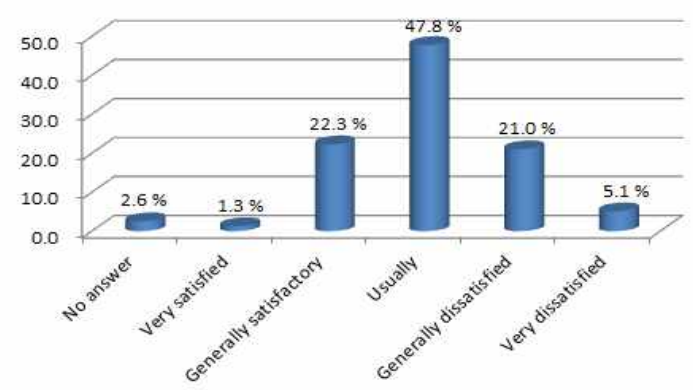

(a) Fidelity of construction drawing

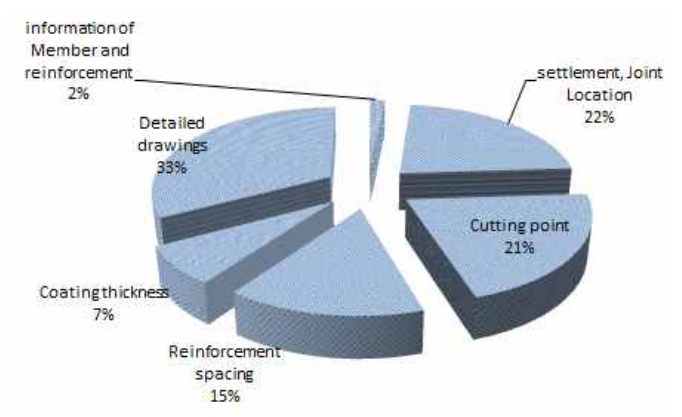

(b) Missing information of structural drawing

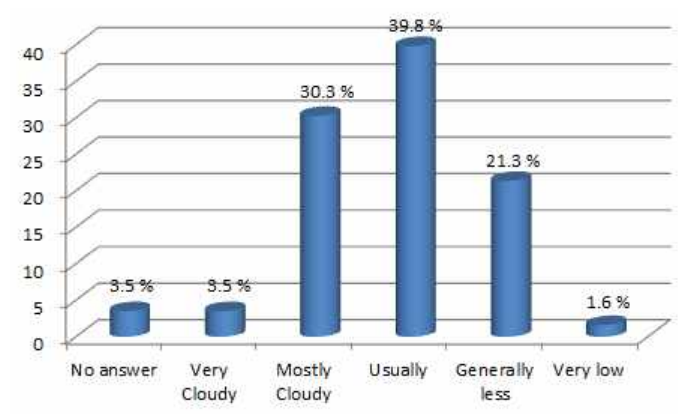

(c) The frequency defects in the structure drawing

Figure 3. The quality of structural drawings I
For the question, 'Have you ever experienced any problem due to the drawings used in construction?' most of the respondents have experienced some problems concerning drawings, as shown in Figure 3(c). Specifically by professional, professional engineers and architects responded very often(40.5\%) $\rangle$ usually $(34.8 \%)>$ overall not frequently(15.7\%), while other technicians such as technician and craftsmen responded usually $(42.6 \%)>$ overall frequently $(27.2 \%)>$ overall not frequently $(23.5 \%)$. The difference in responses by technical qualification, professional engineers and architectures found more problems compared with other technicians, and felt the problems of drawings more seriously as the result.

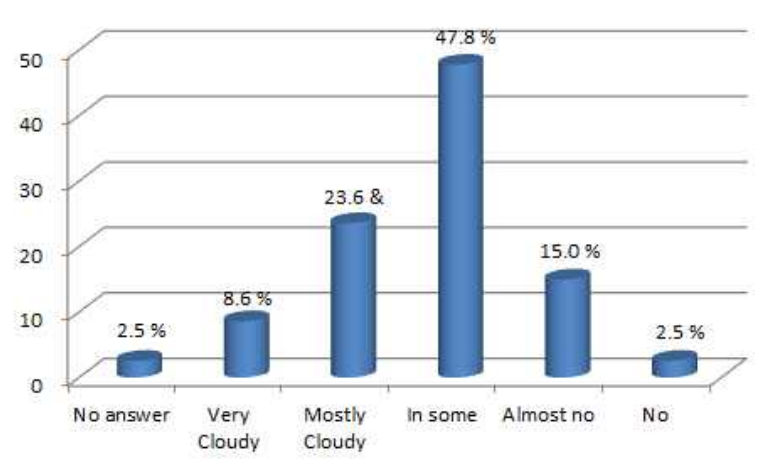

(a) Comparison of structural drawings and structural design

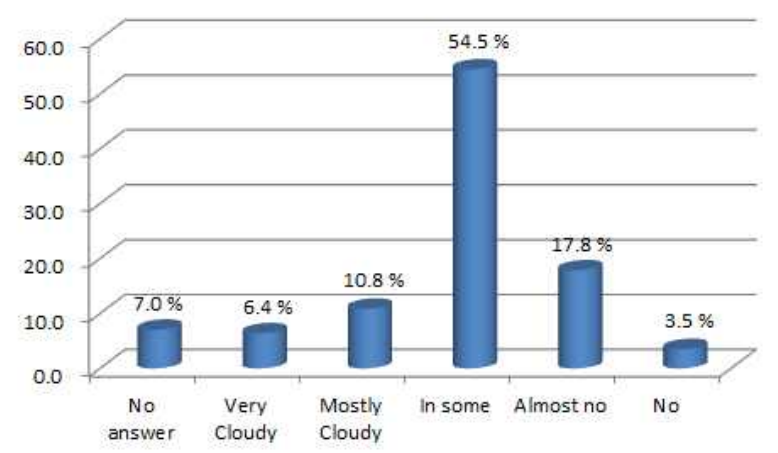

(b) Different structural drawings and structural design description information

Figure 4. The quality of structural drawings II

For the question, 'Have you ever compared the structural drawings and the structural design description(i.e. structural calculation sheet)?' $47.8 \%$ of 
respondents answered 'a few times' and $23.6 \%$ respondents said 'very often, as shown in Figure 4(a).' In addition, for the question, "Were there any differences between the structural drawings and structural design description when you compared them?,' respondents mentioned 'a few differences(54.4\%),' 'few differences(17.8\%), and 'overall many differences(10.8\%), as shown in Figure 4(b).

From the responses, about $80 \%$ respondents have compared the structural drawings and the structural design description because they felt something wrong on the drawing, and $72 \%$ of them answered that there was different information on the drawing from the description. Based on the results, in many cases the structural design drawing currently used in Korea does not deliver basic information provided in the structural description.

For the question, 'Is there a shop drawing at the construction sites?' 9\% of respondents answered 'yes, it was at every construction site they experienced,' while $7 \%$ of respondents responded 'it was not at a single construction site they experienced,' as shown in Figure 5(a). From the responses, most of the respondents experienced construction sites a shop drawing is prepared, and about $50 \%$ of construction sites were found to have a shop drawing.

For the question, 'Do you think a shop drawing brought improvement of constructability?' $53.8 \%$ of respondents answered 'extremely so' and $36.0 \%$ of respondents said 'slightly so,' which indicates that around $90 \%$ of respondents felt that a shop drawing helped improve constructability. By technical qualification, $69.7 \%$ of professional engineers and architects and $51.2 \%$ of other technicians mentioned 'extremely so,' which means that professional engineers and architects see the more necessity of a shop drawing compared with other technicians.

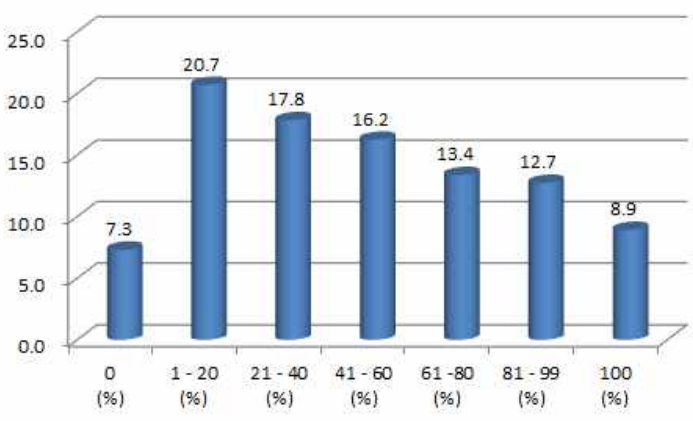

(a) Field experience with construction drawings

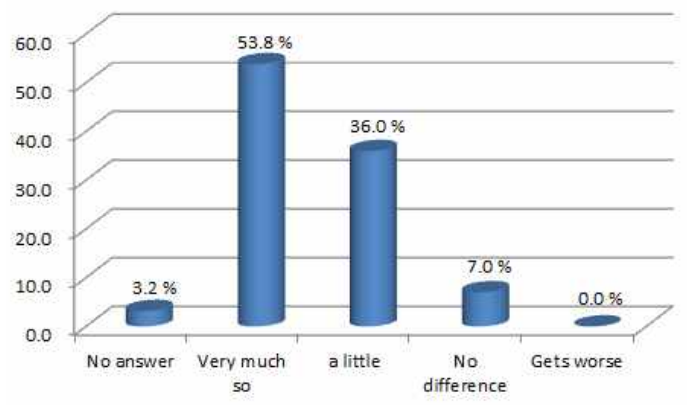

(b) Workability promoting effects of construction drawings

Figure 5. Construction drawings

\subsection{Interviews}

\subsubsection{Outline}

The purpose of the interviews conducted in this research is to understand practices in Korea and to find out improvements by listening to opinions from professionals with regard to the 'effect of the specification of rebar placement on crack occurrence.' The questions on the problems were mainly designed concerning quality of a structural design drawing, and practices and systems to be improved for quality improvement of building structures. Professionals involved in structural design, construction supervision, preparation for a shop drawing, and rebar concrete work were interviewed.

\subsubsection{Results and analysis}

1) What is the quality of a structural design drawing of Korea?

(1) A structural design drawing of advanced for- 
eign countries includes much information including plane and cross-section, and a worker can get an easy 3-dimentional understanding with it. However, the structural design drawing of Korea is short of specified information including members and joints, and only plane or cross-sectional information is included so that workers feel difficulty in constructing a structure with it.

(2) In many cases in Korea, many differences are found in a structural drawing from construction, electricity and equipment drawings, and the differences deteriorate the quality of structural section, ultimately leading to structural interpretation errors and member design errors. This problem is caused by different point of time of designs for professional area(construction, structure, electricity, and machine) and few mutual deliberation between the participants.

(3) The most significant difference between the domestic and overseas drawings lies in the rebar placement specification. Standard specification is mainly described in the domestic structural design drawing, and other details peculiar or unique to each site are not described. In particular, in the case of apartment buildings or small-scale buildings design cost is low and the rebar placement specification is not provided appropriately. For this reason, a supervisor, a non-professional related with structure, mostly interprets the specification based on his/her supervision experiences, and the construction quality varies depending on the supervisor's proficiency and skills.

2) Problems of rebar placemen specification in the structural drawing?

(1) The rebar placement specification in which the conditions of the is not considered is provided. For example, there are many cases that rebars are placed without consideration of horizontal stress put on a connection of the skip-floor slab.

(2) The intent of the designer is not described. For instance, in most of cases the distance between the top and the bottom rebars for the doubly reinforced beams was set at $25 \mathrm{~mm}$ and then calculated, but the designer' $\mathrm{s}$ intention is not described on the drawing and rebars are placed with no consideration of it.

(3) Structural information is very scant on the structural design drawing. For example, if there is no information on location and length for the rebar settlement and connection, it is often found that the welding length and throat thickness are not written.

(4) The construction conditions are not considered in the structural design. For instance, overcrowded rebars at a connection prevent concrete from being filled, structural problems occur because construction load is not considered, and interference like structural members and installed pipes keeps rebars from being placed in a right place, to name a few. 3) Why is the quality of domestic structural drawings lower than that of overseas drawings? The followings are mentioned as the problems;

(1) bad practices and system for the structural design in Korea,

(2) low service cost for structural work and short period of working time,

(3) lack of field experience of structural designers,

(4) lack of deliberation on design by professionals from each field, and

(5) frequent design changes.

4) What are the practices and systems to be improved for quality improvement of building structures? 
(1) In order for the technicians who work at the site not to interpret the structural drawings in their discretion, the intent of the structural designer should be written on the structural drawing, and for the builder to get an easy understanding it should be made easy. To do this, the structural designer should make the structural drawing, and it should be institutionalized in law so that the structural designer is responsible for the quality of the drawing made by himself/herself.

(2) From the structural design aspect, the structural design cost is very low, and the design should be finished within a relatively short period of time, so that it is hard to make a quality design drawing. The structural design cost should be normalized, and enough time for the structural design should be secured. In addition, design changes are not unusual in Korea, but there is no additional cost or very low cost for the design changes, if any.

(3) A structural engineer who has structural knowledge and experiences should participate in the supervision for the structural safety. Through improvement of the system, if a structural engineer participated in the supervision of a construction site, it would be highly helpful for quality improvement of a building structure.

(4) If the information needed for the construction is written on the shop drawing, it can be construction without any help of other construction documents including complicated specifications. The field technicians try to understand the drawings but make little effort to be well-informed or review the details of the specification. The specification is always treated as a formal document.

\section{Drawing and field research}

\subsection{Analysis of a drawing}

\subsubsection{Outline}

The quality of structural design drawing and the shop drawing(hereinafter structural · shop drawings) was analyzed in this study. The analysis aims to analyze the Korea's unique problems of structural $\cdot$ shop drawings that have a direct impact on the quality of structure and to draw an improvement plan. As the analysis method, the information provided on structural - shop drawings of advanced foreign countries including the U.S. was compared with that provided on structural · shop drawings of Korea, and the differences in drawing quality and the causes were analyzed in the center of the information level required for the rebar construction.

\subsubsection{Comparative analysis of domestic and overseas drawings}

1) Preparation for structural design drawings

Structural engineers in foreign countries prepare structural design drawings as well as structural description(simply structural calculation sheet), while structural engineers in Korea prepare only structural design documents. The structural design drawings of Korea are usually prepared by people who do not have enough specialty in the structural field(hereinafter structure-related non-professionals), and the level of drawings is a transcription in part of structural design documents made by a structural engineer.

2) Understanding of a drawing

The structural design drawing should be prepared for builders to understand the information provided on the drawing. Since the quality of a structural design drawing varies in quality depending on the ordering party or the preparing company, Korean and American drawings collected were compared.

(1) Most of American drawings provide abbrevia- 
tions and legends on them including concrete, steel materials, and joints. Figure 6 is an example of some abbreviations and legends shown on American drawings. Abbreviations and legends make the expression of the drawing simple and easy to understand. For instance, 'AB' refers to Anchor Bolt, 'LWC' to Light Weight Concrete, and 'MFB' to Moment Frame Beam, which are very easy to use[6]. In addition, all the abbreviations used on the drawing are enumerated in the abbreviation list of the drawing. Like abbreviations, symbols are also listed, and builders that do not have many field experiences can understand the drawing easily. Compared with American drawings, abbreviations are less used; however, abbreviations of member type (e.g. 'F'(Foundation), 'C'(Column)) and rebar placement ('H'(Horizontal rebar), 'V'(Vertical rebar), 'T/B'(Top/Bottom rebar)' are easily found on Korean drawings. Regardless of the frequency of use of an abbreviation, all the abbreviations used on a drawing should be listed on the general information. However, sufficient effort has not been made for the abbreviation list on the Korean drawings.

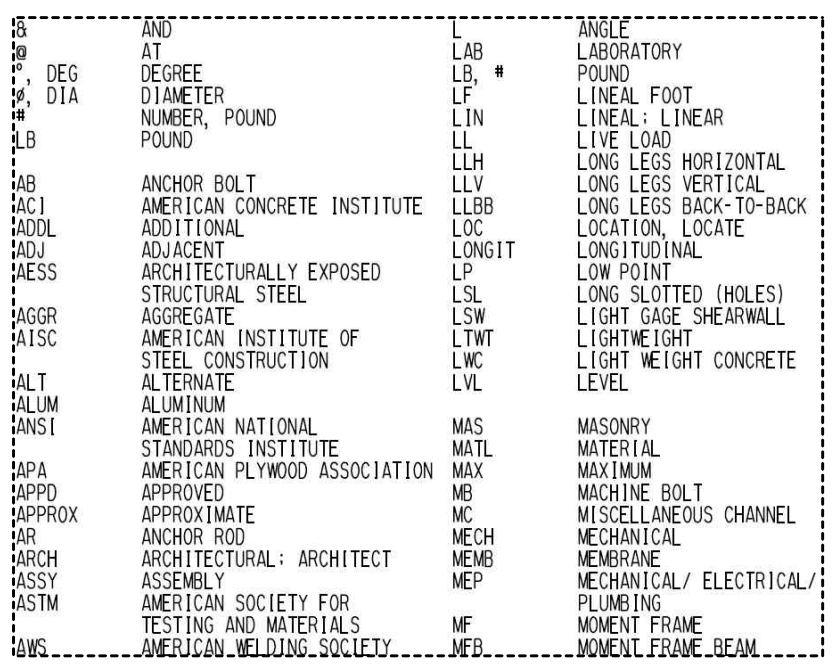

(a) List of abbreviations

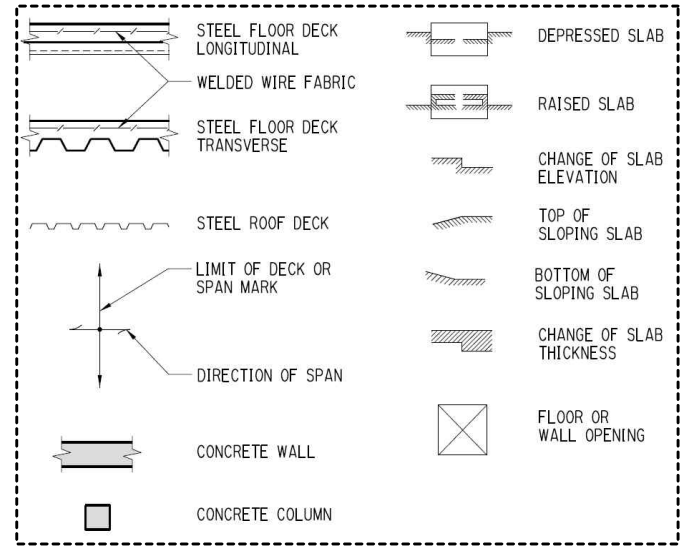

(b) List of symbols - concrete

Figure 6. List of abbreviations and symbols of American Drawings

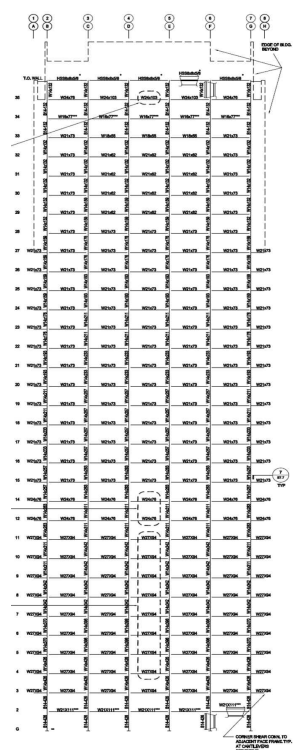

(a) Frame drawing

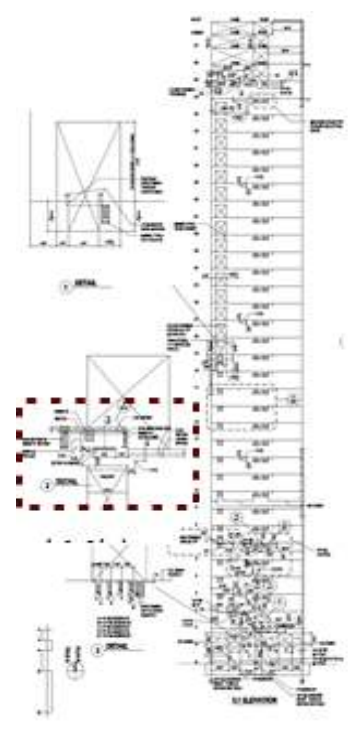

(b) Elevation drawing

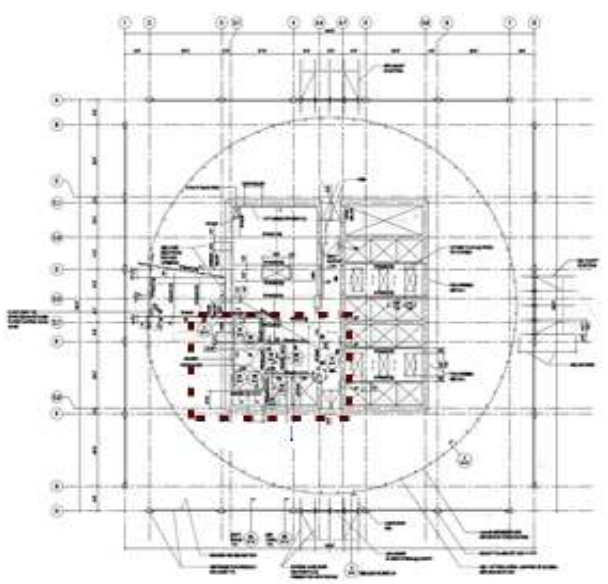

(c) Flat drawing

Figure 7. The overall structure of the United States Information 
(2) To get an easy understanding of a structural design drawing, the entire composition of the structure should be caught at a glance from the drawing. For an easy understanding, a skeleton diagram and an elevation drawing for the entire structure, and floor plans of each level are needed.

Figure 7 shows a skeleton diagram and an elevation drawing for the entire structure, and some of floor plans, which help one to get the entire structural information. Floor plans of each level is basically included in a Korean structural design drawing, but a skeleton diagram and an elevation drawing are often excluded depending on design company or ordering body.

(3) In order to link the overall structural information to detailed information, the detailed information is included in the page related with the information as shown in Figure 7(b), or a connection is used as shown in Figure 7(c). Figure 7(a) shows the enlarged left part of an elevation drawing, and the detailed information related with the elevation drawing is included in the same page.

When the structure is complicated, a connection is used to make an easy link of the entire structural information to the detailed information in an American design drawing. For instance, Figure 7(b) is the enlarged lower part of the floor plan shown in Figure 7(c). The mark '10/S7.9' in the circle has the same meaning of 'SEE 10/S7.9,' which indicates 'follow the construction details of no.10 on page S7.9.'

(4) If the specific details are provided on the drawing clearly enough, the structure can be built accurately without any personal judge on the structure. However, it can be very subjective to determine "which specific details are needed for the construction process,' but the pages that include specific details in the American drawing account for 30 to 40 percent of the entire drawing. When the specific details on each page are added, there are a total of 150 to 250 pieces in number. On the other hand, standard details that structural engineers commonly use in Korea are usually provided, the details provided in the drawing are just 30 to 40 pieces in number.

\subsection{Field research}

\subsubsection{Outline}

As the research method, the drawing used for the structure construction was reviewed and analyzed by paying a visit to the construction site, and visual inspection was conducted for the structure under construction to analyze general errors found in the specification of rebar placement.

\subsubsection{Research on rebar placement at sites}

1) Interval error between top and bottom rebars for the doubly reinforced beams

When the beams are placed in two layers, the interval between top and bottom rebars should be specified[7]. A structural designer generally assumes the location of the top rebar to be the diameter/2+sheath thickness, and the interval between the rebars is often considered as $25 \mathrm{~mm}$. However, if the intent of the designer is not usually specified on the structural drawing, there were some cases found that the interval between top and bottom rebars was set at $60 \mathrm{~mm}$ or $190 \mathrm{~mm}$ by the builder as shown in Figure 8 .

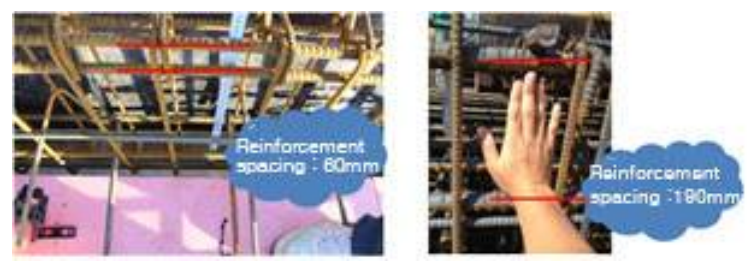

Figure 8. Rebar interval error 


\section{2) Settled position error}

Figure 9 are the cases that tensile rebars placed at a construction site did not have enough development length required. Figure 9(a) shows that slab tensile rebars without hook were placed on the wall, and enough development length was not secured for the rebars. Figure 9(b) shows that tensile rebars on the top did not pass through the center of the section so that there is almost no development length secured. The development length should be sufficiently secured by making the tensile rebars pass through the center of the section of the members to be settled.

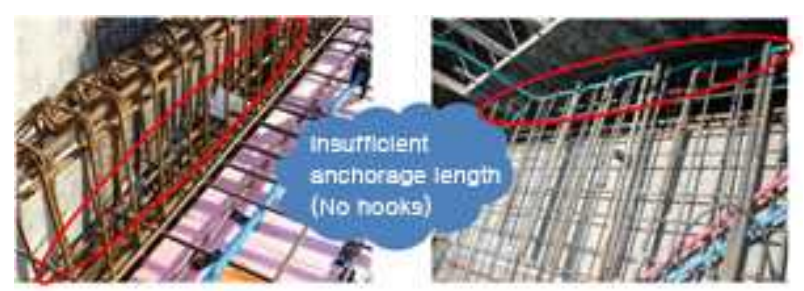

(a) Hooks error

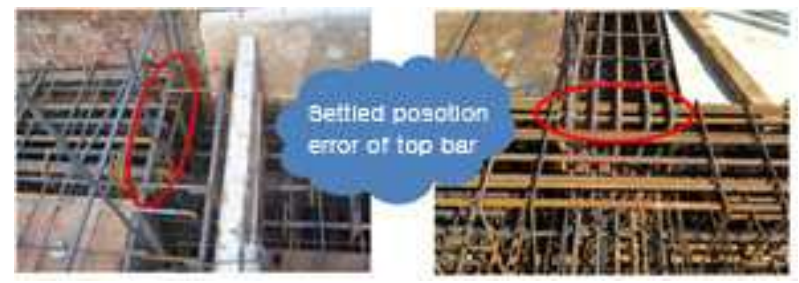

(b) Settled position error

Figure 9. Tensile reinforcement error

3) Rebar-skeleton welding error

When rebar is welded on a skeleton, the information on rebar type, welding length, and throat length should be specified, but the information was omitted at the site. In this case, general rebar not welding rebar is used in welding, and welding is done with no consideration of welding length and throat thickness.

4) Structural error caused by equipment box on the wall

When a equipment box is installed on the wall, it is often the case that it is worked without any review on the structure but only in consideration of convenience of the work. Figure 10 shows the case that when the rebars were interfered with the equipment box on the wall, the horizontal and vertical rebars were cut.

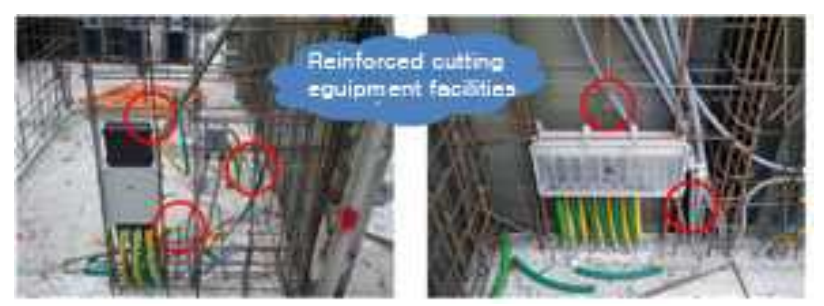

Figure 10. Wall of the horizontal and vertical rebar cutting error

5) Error caused by interference of equipment box with rebars in the slab

When rebars are interfered with the electricity box in the slab, as shown in Figure 11 the tensile rebars on the bottom that should have been placed in the slab were placed on the electricity box. When the tensile rebars are placed on the electricity box, the effective depth of the tensile rebars decreases, and bending strength lowers and cracks can occur around the electricity box.
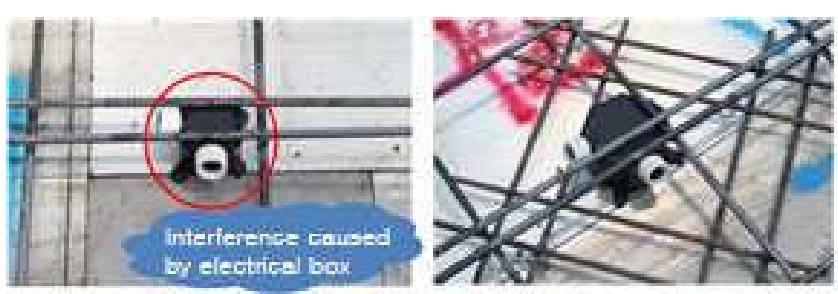

Figure 11. Failure of equipment and reinforcement in the slab

\section{Conclusion}

In this research, the causes of cracks were considered from the structural perspective, and the actual state was analyzed. The improvement plan for the quality of rebar concrete structure is suggested as follows: 


\section{Acknowledgement}

This research was supported by Reinforced Concrete

Works Council of Korea.

\section{References}

1. Civil Engineering Research Information Center [Internet]. Seoul (Korea); c2000-2013[cited 2013 May 10]. Available from: http://www.ceric.net

2. National Research Information Center [Internet]. Seoul (Korea); c2013[cited 2013 May 18]. Available from: http://www.auric.or.kr

3. Ahn YS, Kim JT, Hong SW. A study on types of and countermeasures against defects in constructing apartment houses. Journal of the Architectural Institute of Korea. 2004 Nov;6(4):85-92.

4. Song H, Ko SS, Jang SR. Analysis of Defect Cases by Construction Types in Apartments. Journal of the Korean Society of Safety. 2006 Oct;21(6):64-73.

5. Park SU. Study on the defect prevention of reinforced concrete structure [master's s thesis]. [Seoul (Korea)]: Konkuk University; 2011. $105 \mathrm{p}$.

6. ACl Committee 318. Building Code Requirements for Structural Concrete (ACI 318-11) and Commentary. American Concrete Institute. 2011.

7. Korea Concrete Institute. Concrete structural design criteria. 4th ed. Seoul (Korea): Kimoondang; c2011. Chapter 5, Reinforcement details; p. 91-110. Korean.

8. Korea Ministry of Government Legislation [Internet]. Seoul (Korea); c1997-2013[cited 2013 June 12]. Available from: http://www.law.go.kr

9. Architectural Institute of Korea. Building construction standards. 5th ed. Seoul (Korea): Kimoondang; c2010. Chapter 5, Concrete Structure; p. 120-143. Korean. 